\title{
Measurements of RF Radiation in the Vicinity of FM and TV Broadcasting Stations
}

\author{
Abdulaziz S. Al-Ruwais \\ Department of Electrical Engineering, College of Engineering, King Saud University, \\ P.O. Box 800, Riyadh 11421, Saudi Arabia.E-mail: asruwais@ksu.edu.sa
}

قيلسلت للإثماع اللسكي عل مقربةمنمحلت البث التلزبوف وراليو (FM)

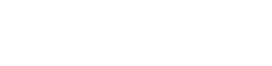

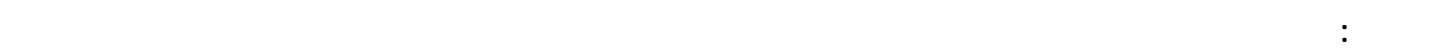

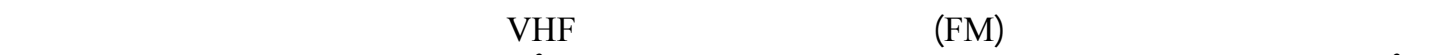

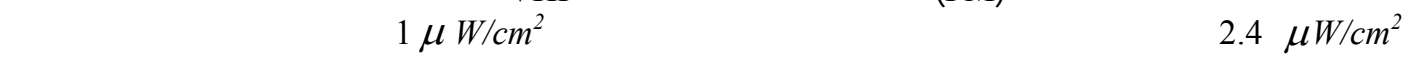

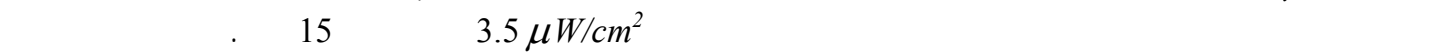

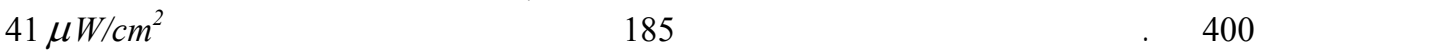
وذلك على ارغفاع 18 مترمنسطح الأرض .

\begin{abstract}
This paper provides measurements of power density around an FM and VHF-TV broadcasting station and its variation with distance. The maximum measured value was about 2.4 $\mu \mathrm{W} / \mathrm{cm}^{2}$ at a height of 2 meters above ground level while the average value was fluctuating around 1 $\mu \mathrm{W} / \mathrm{cm}^{2}$. It was found that the measured power density increases with height above ground and it reaches about $3.5 \mu \mathrm{W} / \mathrm{cm}^{2}$ at a height of about 15 meters at a location of about 400 meters from the station. At a nearer distance of 185 meters from the tower another measurement was taken at a height of 18 meters, the power density increased to $41 \mu \mathrm{W} / \mathrm{cm}^{2}$.
\end{abstract}

KEYWORDS: Power density, Antennas, Broadcasting Towers.

\section{Introduction}

$\mathbf{T}$

elevision and FM radio broadcasting is now widely used in most countries. The need for full coverage with TV and FM radio has resulted in many lower power repeater transmitters being used to bring the services to local communities. High power antennas for TV broadcasting are usually mounted on very high towers. FM radio broadcast antennas are often mounted on the same tower as the TV VHF and UHF antennas. It is almost common now to see these radio and TV broadcasting towers situated in the center of cities all over the world where residential and economic centers are located.

The radio frequency (RF) radiation from broadcasting transmission has led to some regulation and control limits in some countries. Radiation measurements from FM/TV towers indicate that workers inside buildings adjacent to the towers are exposed to intense electric and magnetic fields, which sometimes exceed the radiation safety standards (Tell, 1978). In special cases, radiation hazards may also extend beyond the broadcasting station. Tell (1976) in the United States, Jokela (1998) in Finland and Sahalos et al. (1995) in Greece are among the researchers who have dealt with radiation hazards outside the FM/TV broadcasting towers. This paper presents power density measurements around a radio FM and VHF-TV broadcast antenna tower situated in the center of Riyadh, Saudi Arabia. These measured values have been discussed and compared with radiation safety standards. In general, the maximum exposure 
limits of RF radiation vary with frequency. In the frequency range of VHF TV/FM broadcasting, the Maximum Exposure Limits for general public (uncontrolled exposure) are 200 $\mu \mathrm{W} / \mathrm{cm}^{2}$ for Americal National Standard Institute (ANSI)/IEEE (1992), Federal Communications Commission (FCC) (1997), CENELEC (1995), Finnish (1989) and Japanese (1994) standards guidelines. However, it is comparatively lower $\left(2.3 \mu \mathrm{W} / \mathrm{cm}^{2}\right)$ for the ex-USSR standard (1984).

\section{Sources of TV/FM Radiation and Measurement Procedure}

The FM radio in Riyadh transmits 3 programs at 97.7, 100 and $102 \mathrm{MHz}$ with maximum input power to the antenna of $3 \mathrm{~kW}$ for each. The TV station transmits two TV programs at VHF band III (175 and $182 \mathrm{MHz}$ ) with $10 \mathrm{~kW}$-input power for each channel. The maximum effective radiated power of the FM station is $13.64 \mathrm{~kW}$ for each program. The corresponding value of the TV station is $85 \mathrm{~kW}$ for each program. The FM and TV stations are located in downtown Riyadh and their transmitting antennas are on the same tower, which is at a height of $170 \mathrm{~m}$ above ground level. The largest dimension of the transmitting antennas is about $11.53 \mathrm{~m}$ and $12.25 \mathrm{~m}$ for the FM and TV stations, respectively. The FM antenna consists of 2 dipole panels of dimensions [2.3 $\mathrm{m} \times 2.3 \mathrm{~m}$ ] with 4 panels on each of the four faces. The TV antenna has similar characteristics with 4 dipole panels of dimensions [ $3 \mathrm{~m} \mathrm{x} 1.45 \mathrm{~m}$ ] with 4 panels on each of the four faces.

The power density is measured using Narda RF Radiation Survey meter model 8718 with isotropic probe model 8760 that covers the frequency range from $300 \mathrm{kHz}$ to one $\mathrm{GHz}$. The fullscale measurement is $20 \mu \mathrm{W} / \mathrm{cm}^{2}$ and the response time is selected to be 0.3 seconds. The meter accuracy is $\pm 1 \%$ and calibrations are carried out periodically by the instrument manufacturer.

During measurements, the probe is placed on a wooden tripod stand $2 \mathrm{~m}$ high. The meter is programmed such that it performs 4 measurements within a time interval of 6 minutes, automatically computes their "average value" as well as their "maximum" and then displays these two values on its screen when measurements are being made. Both "average" and "maximum" values are recorded for every measurement. A distance of about $2 \mathrm{~m}$ is always maintained between the body of the operator and the probe.

\section{Power Density Calculations}

The far field power density around a typical broadcasting antenna can be expressed by (Jokela ,1998).

$$
\mathrm{S}=\frac{\mathrm{GF}_{\mathrm{v}}(\theta) \mathrm{F}_{\mathrm{h}}(\phi) \mathrm{P}}{4 \pi \mathrm{r}^{2}}=\frac{\operatorname{EIRPF}_{\mathrm{v}}(\theta) \mathrm{F}_{\mathrm{h}}(\phi)}{4 \pi \mathrm{r}^{2}}
$$

where $\mathrm{S}$ is the power density $\left(\mathrm{W} / \mathrm{m}^{2}\right), \mathrm{G}$ is the maximum gain of the antenna with reference to an isotropic radiator, $F_{v}(\theta)$ is the vertical radiation pattern, $F_{h}(\phi)$ is the horizontal radiation pattern, $\mathrm{P}$ is the input power of the antenna $(\mathrm{W})$, and $\mathrm{r}\left(=\sqrt{\mathrm{d}^{2}+\mathrm{h}_{\mathrm{a}}^{2}}\right)$ is the distance from antenna to observation point $(\mathrm{m})$. Here $\mathrm{d}$ is the horizontal distance from the base of the antenna tower and $h_{a}$ is the height of antenna above ground level, $\theta, \phi$ are polar and azimuthal angle's (radians), respectively, EIRP is the effective isotropically radiated power $=\mathrm{GP}$, and $\mathrm{F}_{\mathrm{v}}(\theta)$ and $\mathrm{F}_{\mathrm{h}}(\phi)$ are normalized to unity in the direction of maximum radiation. Since the horizontal radiation pattern is essentially omnidirectional, then $\mathrm{F}_{\mathrm{h}}(\phi)$ can be assumed to be equal to 1 . The vertical radiation pattern is not always available and therefore a relative gain factor $(\mathrm{F})$ can be used instead, as recommended by the FCC report (OET Bulletin 65) (FCC, 1997). Furthermore, the U.S. Environmental Protection Agency (EPA) has suggested (Gailey and Tell, 1985) an increase factor in power density of 2.56 due to ground reflection around FM radio and TV 
broadcast antennas. Based on these two suggestions, a simpler form of the above equation can be derived where the power density is expressed in $\mu \mathrm{W} / \mathrm{cm}^{2}$ (FCC, 1997).

$$
\mathrm{S}=\frac{33.4 \mathrm{~F}^{2} \mathrm{ERP}}{\mathrm{r}^{2}}
$$

with ERP being the effective radiated power with reference to a half-wave dipole in watts, EIRP equals 1.64 ERP, and $\mathrm{F}$ the relative field factor (relative numeric gain). The factor $\mathrm{F}$ (derived from relative power gain) is determined from the antenna's vertical radiation pattern if it is available. If not, $\mathrm{F}$ is estimated. When the point of observation is in or near the main radiated beam, it can be assumed to be 1. For an FM broadcast antenna, "the best case element studied by the EPA had a maximum downward radiation field factor of less than 0.2 compared to the approximate 1.0 maximum for a dipole element" (FCC, 1997). The EPA developed a computer model for estimating ground level power densities in the vicinity of some typical FM broadcast towers (FCC, 1997). The FCC's version of this FM computer model is available on the FCC World Wide Web site. The EPA has also developed (FCC, 1997) the following formula to predict the power density at the base of TV broadcasting towers and is given by

$$
\mathrm{S}=\frac{33.4 \mathrm{~F}^{2}\left[0.4 \mathrm{ERP}_{\mathrm{V}}+\mathrm{ERP}_{\mathrm{A}}\right]}{\mathrm{r}^{2}} \mu \mathrm{W} / \mathrm{cm}^{2}
$$

where $\mathrm{ERP}_{\mathrm{v}}$ is the total peak visual ERP in watts, and $\mathrm{ERP}_{\mathrm{A}}$ is the total aural ERP in watts.

The factor of 0.4 converts peak visual ERP to an RMS value which is more realistic with regard to practical conditions of video transmission. An average value of $F=0.2$ is suggested by EPA for VHF-TV antenna radiating in the downward direction.

At multiple transmitter sites where several RF sources and frequencies are involved, the FCC regulations require calculating the fraction of the recommended limit incurred within each frequency interval and then taking the sum of all fractional contribution. In our case, however, the Maximum Exposure Limit of the FM and VHF-TV is determined by most of standards at $200 \mu \mathrm{W} / \mathrm{cm}^{2}$. Therefore, using equations (2) and (3) the total power density from such multiple sources can be expressed as

$$
\mathrm{S}=\frac{33.4 \mathrm{~F}^{2}\left[\mathrm{ERP}(\mathrm{FM})+0.4 \mathrm{ERP}_{\mathrm{V}}(\mathrm{T} . \mathrm{V})+\mathrm{ERP}_{\mathrm{A}}(\mathrm{T} . \mathrm{V})\right]}{\mathrm{r}^{2}}
$$

Table 1: Calculated values of power density around the radio FM and VHF-TV broadcasting antenna in Riyadh.

\begin{tabular}{|c|l|c|}
\hline$r$ (meters) & $F$ & $\begin{array}{c}\mathrm{S}_{\mathrm{c}} \\
\left(\mu \mathrm{W} / \mathrm{cm}^{2}\right)\end{array}$ \\
\hline 100 & 0.1 & 0.93 \\
200 & 0.12 & 0.76 \\
300 & 0.15 & 0.69 \\
400 & 0.17 & 0.57 \\
500 & 0.2 & 0.52 \\
600 & 0.21 & 0.41 \\
700 & 0.22 & 0.34 \\
800 & 0.22 & 0.29 \\
900 & 0.24 & 0.25 \\
1000 & 0.25 & 0.22 \\
1100 & 0.25 & 0.18 \\
\hline
\end{tabular}

where $\mathrm{S}$ is the power density in $\mu \mathrm{W} / \mathrm{cm}^{2}$ and $\mathrm{ERP}(\mathrm{FM})$ is the effective radiated power from the radio FM transmitter. Applying equation (4) and using the data given in section II, the results are tabulated in Table 1. The values used for the F factor are shown in the F-column of Table 1. 


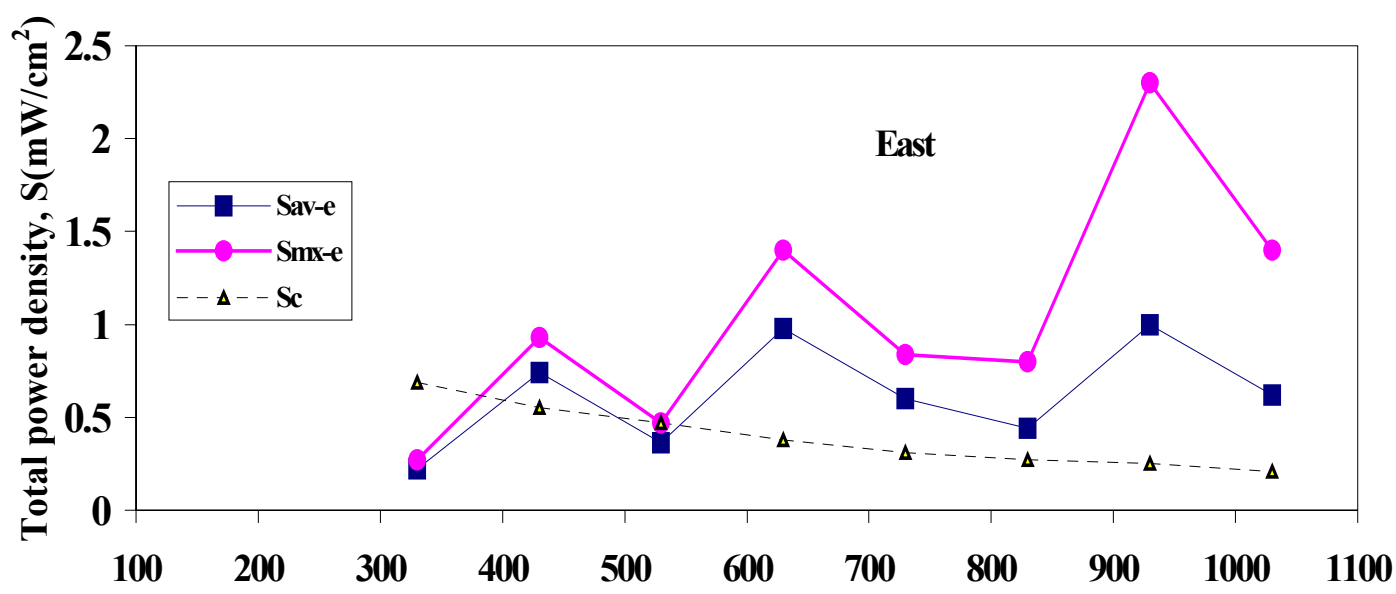

Distance from tower, $\mathrm{d}(\mathrm{m})$

Figure 1. Variation of the maximum $\left(\mathrm{S}_{\mathrm{max}-\mathrm{e}}\right)$ and average $\left(\mathrm{S}_{\mathrm{av}-\mathrm{e}}\right)$ power density with distance from tower in the east direction.

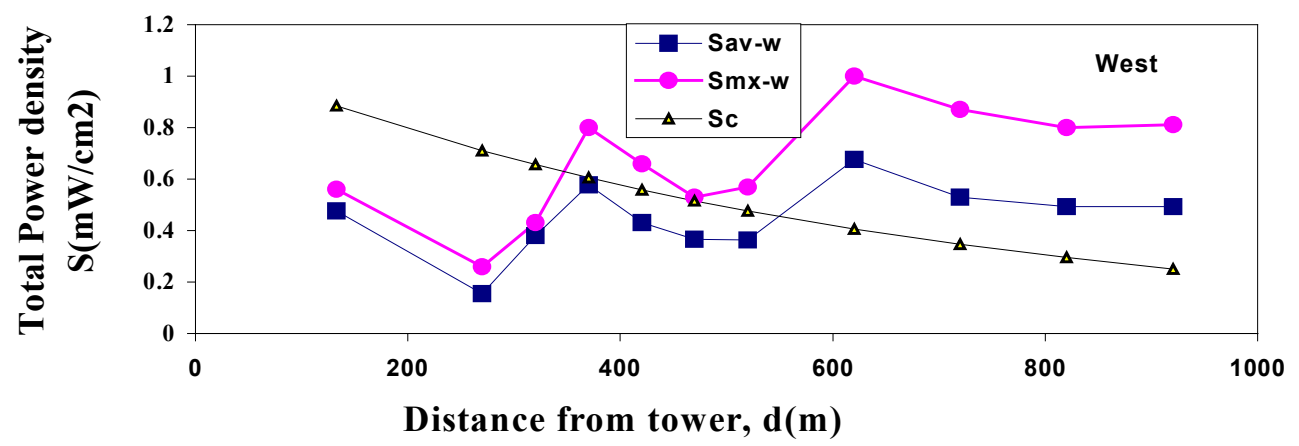

Figure 2. Variation of the maximum $\left(\mathrm{S}_{\max -\mathrm{w}}\right)$ and average $\left(\mathrm{S}_{\mathrm{av}-\mathrm{w}}\right)$ power density with distance from tower in the west direction.

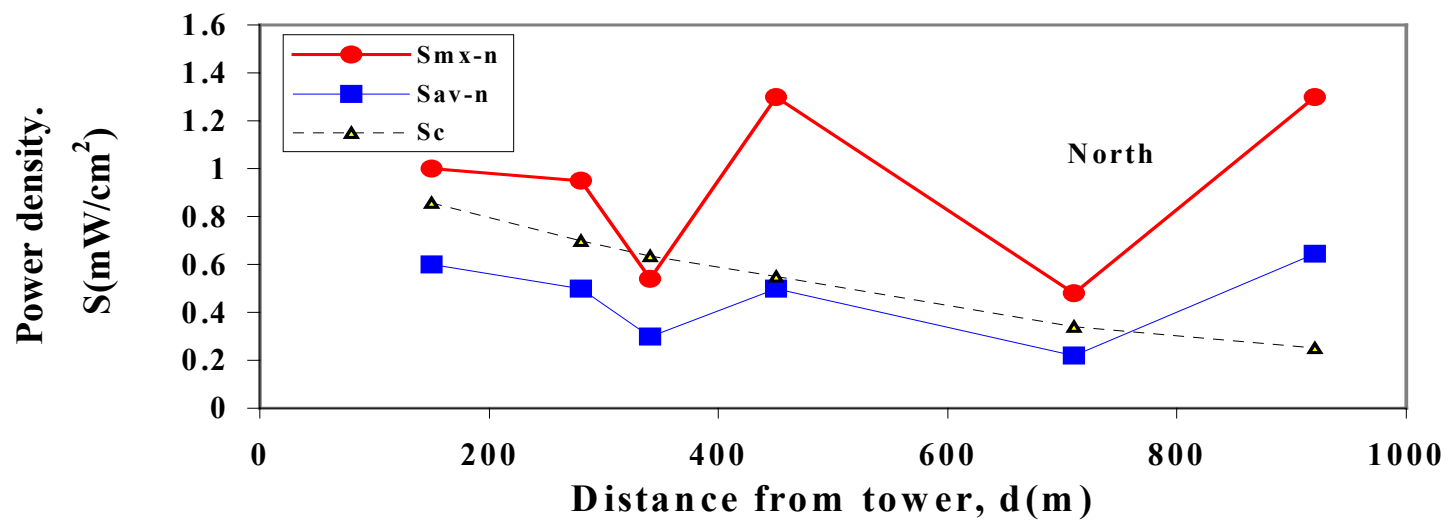

Figure 3. Variation of the maximum $\left(S_{\max -n}\right)$ and average $\left(S_{a v-n}\right)$ power density with distance from tower in the north direction.

The values were chosen so that they fluctuate around the average value of $\mathrm{F}=0.2$, which is suggested by the EPA. 


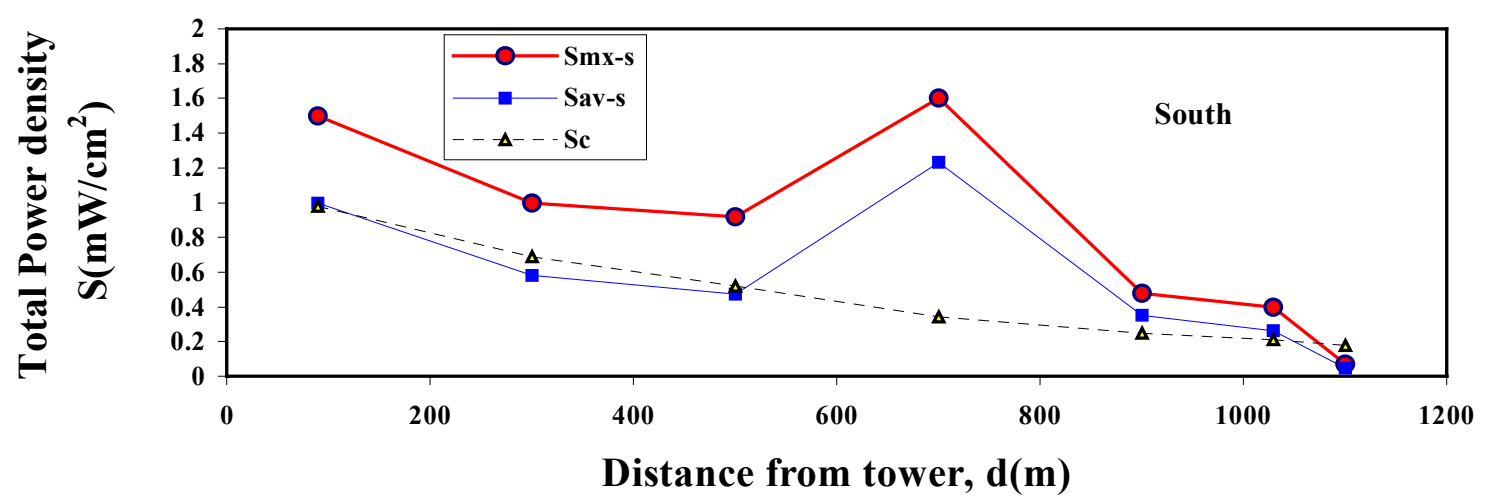

Figure 4. Variation of the maximum $\left(\mathrm{S}_{\mathrm{max}-\mathrm{s}}\right)$ and average $\left(\mathrm{S}_{\mathrm{av}-\mathrm{n}}\right)$ power density with distance from tower in the south direction.

\section{Results and Discussion}

Measurements of power density generated from the VHF-TV/FM antenna were taken in four directions from the antenna. The measurements started at about $70 \mathrm{~m}$ from the antenna tower and were repeated at several locations until about $1200 \mathrm{~m}$ in the four directions, East, West, North and South. The results of the measurements of the "maximum" and "average" values of the power density in the four directions are shown in Figures 1- 4. The maximum (average) is defined as the maximum (average) value of the four measurements performed by the meter within 6 minutes time interval as previously explained in section 2 . These results show clear variations of the measured power densities with distance as well as direction due to the effects of the surrounding environment. The calculated results of power density are also shown in these Figures for comparison. The theoretical results reasonably agree with the measured values except at some locations where the theoretical model fails to predict complex reflections or due to the effects of possibly other nearby RF transmitters. The greatest measured maximum value of the power density reached was about $2.4 \mu \mathrm{W} / \mathrm{cm}^{2}$ in the east direction at a distance of about $870 \mathrm{~m}$ from the antenna tower. The average value of this measured power density is about $1 \mu \mathrm{W} / \mathrm{cm}^{2}$. Figure 5 shows the measured variation of the power density with height at a residential building $435 \mathrm{~m}$ distance from the tower. The increase of power density with height is evident and reaches its maximum value of about $3.5 \mu \mathrm{W} / \mathrm{cm}^{2}$ at a height of about $15 \mathrm{~m}$ and a distance $435 \mathrm{~m}$ from the tower. On the top roof of another higher building $(\mathrm{h}=18$ $\mathrm{m})$ and nearer to the tower $(\mathrm{d}=185 \mathrm{~m})$, the maximum and average values of the power density are the same and reach about $41 \mu \mathrm{W} / \mathrm{cm}^{2}$. The measured values are below the well-known standards, which is about $200 \mu \mathrm{W} / \mathrm{cm}^{2}$ excluding the Russian standard, which is about 2.3 $\mu \mathrm{W} / \mathrm{cm}^{2}$ at the $\mathrm{FM} / \mathrm{TV}$ VHF band.

The location at $185 \mathrm{~m}$ of the TV tower is considered in the far field region. Therefore the measured plane wave power density in Riyadh at this distance from the TV tower and $18 \mathrm{~m}$ height $\left(41 \mu \mathrm{W} / \mathrm{cm}^{2}\right)$ is about 20 times higher than the maximum measured value in a village north of TV and FM tower in Greece (Sahalos et al., 1995). On the other hand, it is of the same order of magnitude of measurements carried out by Jokela (1988) for an average feed power of $4 \mathrm{~kW}$, and at a height of $300 \mathrm{~m}$ and at a distance of about $180 \mathrm{~m}$ in front of the midpoint of the TV antenna. At $2 \mathrm{~m}$ above ground level and within distances, $\mathrm{d}$, such that $90 \mathrm{~m}<\mathrm{d}<1200 \mathrm{~m}$ from VHF-TV/FM tower, the average power density in Riyadh is close to the exposed level of $1 \%$ of the population of 15 cities in USA (Tell, 1980). 


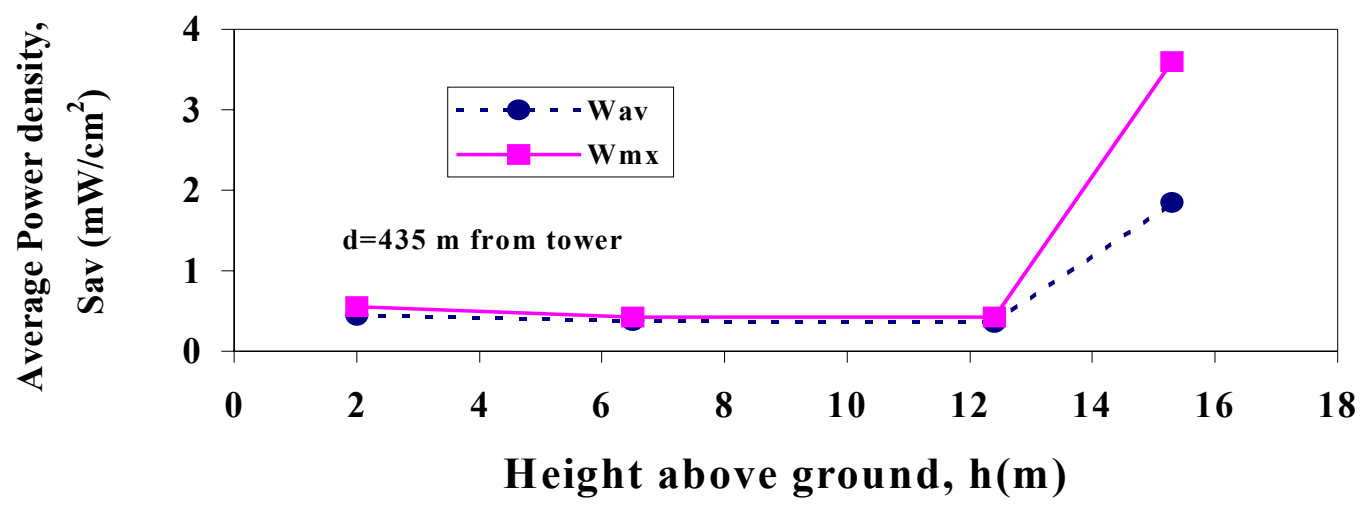

Figure 5. Variation of power density with height at a residential building $435 \mathrm{~m}$ from the tower.

\section{Conclusions}

Measurements of power density around an FM and VHF TV broadcasting station are provided. Calculated results are also included. The maximum measured value was about 41 $\mu \mathrm{W} / \mathrm{cm}^{2}$ at a distance of $185 \mathrm{~m}$ from the antenna tower and at a height of $18 \mathrm{~m}$ from ground level. All the results are below the maximum exposure limit $\left(200 \mu \mathrm{W} / \mathrm{cm}^{2}\right)$ established by the standards, for FM radio and VHF TV broad-casting.

\section{Acknowledgement}

This work was supported by King Abdulaziz City for Science and Technology (KACST), under grant Number AT-1554. The author would like to thank Dr. Abobakr Sultan, and Mr. Nasser Mohy Eldin for carrying out the measurements. The helpful discussion with Dr. Z.O. AlHekail, Prof. H.S. Afifi, and Dr. F.A. Alhargan are appreciated.

\section{References}

AMEMIYA, Y. 1994. Research on biological and electromagnetic environments in RF and microwave regions in Japan, IEICE Trans. Communications. E77-B: 693-698.

AMERICAN NATIONAL STANDARDS INSTITUTE (ANSI),1992. Safety levels with respect to human exposure to radio frequency Electro-magnetic fields, $3 \mathrm{kHz}$ to $300 \mathrm{GHz}$, ANSI/IEEE C95.1-1992, IEEE, New York, USA. Available at http://www.fcc.gov/oet/info/software.

CENELEC, 1995. Human exposure to electromagnetic fields. High frequency (10 GHz to 300 $\mathrm{GHz}$ ), ENV 50166-2, Jan.

CENTRAL HEALTH and EPIDEMIOLOGICAL ADMINISTRATION,1984. Interim health standards and regulations on protecting the general population from the effects of the electromagnetic fields generated by radiotransmitting equipment, USSR Administer of Health, Moscow.

FEDERAL COMMUNICATIONS COMMISSION (FCC),1997. Evaluating compliance with FCC guidelines for human exposure to radio frequency electromagnetic fields," OET Bulletin 65.Ed./97-01, Aug.

FEDERAL COMMUNICATIONS COMMISSION (FCC),1997. Evaluating Compliance with FCC guidelines for human exposure to radio frequency electromagnetic fields, Additional information for radio and television broadcast stations, Supplement A (Edition 97-01).

GAILEY, P.C. and TELL, R.A. 1985. An Engineering Assessment of the Potential Impact of Federal Radiation Protection Guidance on the AM, FM and TV Broadcasting Services, 
U.S. Environmental Protection Agency, Report No. EPA 520/6-85-011, April 1985 NTIS order No. PB85-245868.

JOKELA, J., 1988. Theoretical and measured power density in front of VHF/UHF broadcasting towers, Health Physics, 54: 533-543.

JOKELA, K., 1989. Finnish exposure standards, SSI-report 89-15, Second Nordic Meeting on Non-ionizing Radiation.

SAHALOS, J.N., VAFIADIS, E.E., SAMARAS, T.S., BABAS, D.G. and KHOUKOURLIS, S.S., 1995. EM field measurements in the vicinity of an antenna park for radiation hazard purposes, IEEE Trans. On Broadcasting, 41: 130-134.

TELL, R.A., 1978. Measurements of radio-frequency field intensity in buildings with close proximity to broadcast stations, Washington, DC, U.S. Environmental Protection Agency, Office of Radiation Programs, Report ORP/EAD-78-3.

TELL, R.A.A., 1976. Measurements of RF intensities in the immediate vicinity of a FM broadcast station antenna, Silver Spring, MD, U.S. Environmental Protection Agency, Office of Radiation Programs, Tech. Note ORP/EAD-76-2.

TELL, R.H. and MANITPLY, E.D., 1980. Population Exposure to VHF and UHF Broadcast Radiation in the United States, Proceedings of the IEEE, 68: 6-12, Jan.

Received 26 August 2000

Accepted 30 January 2001 